\title{
New or used? Investment with credit constraints*
}

\author{
Andrea L. Eisfeldt ${ }^{\dagger}$ \\ Northwestern University
}

\author{
Adriano A. Rampini ${ }^{\ddagger \S}$ \\ Duke University
}

March 2007

\begin{abstract}
Used capital is cheap up front but requires higher maintenance payments later on. We argue that the timing of these investment cash outflows makes used capital attractive to financially constrained firms, since it is cheap when evaluated using their discount factor. In contrast, it may be expensive from the vantage point of an unconstrained agent. We provide an overlapping generations model and determine the price of used capital in equilibrium. Agents with less internal funds are more credit constrained, invest in used capital, and start smaller firms. Empirically, we find that the fraction of investment in used capital is substantially higher for small firms and varies significantly with measures of financial constraints.
\end{abstract}

JEL Classification: D92; E22; G31.

Keywords: Investment; Used capital; Financial constraints; Vintage capital

*We thank Andrew Abel, Jeffrey Campbell, Larry Christiano, Janice Eberly, John Haltiwanger, Steven Kaplan, Vojislav Maksimovic, Mitchell Petersen, Valerie Ramey, Joshua Rauh, James Schmitz, and Linda Vincent, and seminar participants at Northwestern, Iowa, Illinois (at Urbana-Champaign), Wharton, LBS, the U.S. Census Bureau, Maryland, Wisconsin, Chicago, MIT, Michigan State, UCLA, NYU, Purdue, Indiana, Harvard, Yale, the Federal Reserve Bank of Chicago, Minneapolis, and New York, the 2004 SED Annual Meeting, the 2005 AFA Annual Meeting, the 2005 Midwest Macroeconomics Meetings, and the 2005 NBER Summer Institute on Capital Markets and the Economy and on Corporate Finance for helpful comments and Olesya Baker and Phil Doctor for excellent research assistance. We also thank Lynn Riggs from the Chicago Research Data Center of the Bureau of the Census for assistance with the data. We gratefully acknowledge research support from the Searle Fund.

${ }^{\dagger}$ Department of Finance, Kellogg School of Management, Northwestern University, 2001 Sheridan Road, Evanston, IL, 60208. Phone: (847) 491-7843. Email: a-eisfeldt@northwestern.edu.

${ }_{\ddagger}^{\ddagger}$ Duke University, Fuqua School of Business, 1 Towerview Drive, Durham, NC, 27708. Phone: (919) 660-7797. Email: rampini@duke.edu.

$\S$ DISCLAIMER: The research in this paper was conducted while the authors were Census Bureau research associates at the Chicago Census Research Data Center. Research results and conclusions expressed are those of the author and do not necessarily indicate concurrence by the Bureau of the Census. This paper has been screened to insure that no confidential data are revealed. Support for this research at the Chicago RDC from NSF (awards no. SES-0004335 and ITR-0427889) is also gratefully acknowledged. 


\section{Introduction}

Why invest in used capital rather than new capital? We argue that firms which are credit constrained purchase used capital because the timing of the necessary cash outflows is such that used capital relaxes credit constraints. The purchase price of used capital is lower than that of new capital. However unlike new capital, used capital requires substantial maintenance payments down the road. The timing inherent in these cash flows makes used capital more attractive to firms which are credit constrained at the time of investment. By investing in used capital, constrained firms can operate at a larger scale.

We develop an overlapping generations model in order to study the decision to invest in new or used capital along with the equilibrium in the market for used capital. New and used capital are perfect substitutes in production, but used capital requires a maintenance payment subsequent to purchase. ${ }^{1}$ Agents can only borrow against a fraction of the resale value of capital and differ in their initial endowments of internal funds. We find that agents which have few internal funds are credit constrained, invest in used capital, and start smaller firms. The model hence predicts that the fraction of capital investment comprised by used capital is decreasing in the size of the firm and increasing in the extent to which the firm is financially constrained.

In equilibrium, used capital is expensive when valued using the discount factor of an unconstrained firm, but cheap when valued at the discount factor of a constrained firm. The opposite is true for new capital. The variation in the multiplier on the credit constraint introduces a wedge between the valuations of constrained and unconstrained investors. In the model, any agent who invests in used capital must be credit constrained. Thus, one can observe how credit constrained a firm is through revealed preference in the choice between new and used capital. The convenience yield used capital provides by relaxing constrained agents' credit constraints pushes up the equilibrium price of used capital so that it becomes expensive for unconstrained agents. Moreover, since capital can be sold as used capital after use in production, the higher equilibrium price of used capital in the presence of constrained agents makes investment in new capital even more attractive to unconstrained agents.

We find empirically that the fraction of investment comprised by used capital is indeed decreasing with firm size and varies significantly with measures of financial constraints with the predicted sign. This is true for capital overall as well as for structures and

\footnotetext{
${ }^{1}$ The importance of maintenance costs have been stressed by McGrattan and Schmitz (1999), who find that spending to maintain and repair both equipment and structures averaged $30 \%$ of spending on all new physical capital in Canadian data. Alternatively, the maintenance costs can be interpreted as higher operating costs.
} 
equipment separately. We use data from the Vehicle Inventory and Use Survey (VIUS) and data from the Annual Capital Expenditures Survey (ACES), which samples nonfarm businesses, both by the Bureau of the Census. We are among the first to use the ACES micro data. ${ }^{2}$ We use data from Compustat for financial variables. Owners of smaller vehicle fleets purchase a much larger fraction of their fleet used than those with large fleets. ${ }^{3}$ Similarly, the fraction of capital expenditures on used capital decreases across asset size deciles from about $28 \%$ in the smallest size decile to about $10 \%$ in largest size decile. ${ }^{4}$ We argue that, as in our model, smaller businesses are more likely to be credit constrained, and therefore purchase more used capital which in turn relaxes these constraints. We also show that the fraction of investment in used capital varies with measures of financial constraints such as dividends, leverage, cash, credit ratings, and the Kaplan and Zingales (1997) and Whited and Wu (2006) indices with the predicted sign.

We conclude that financial constraints appear to affect the composition of investment, and not just the level. These facts are not only important for understanding used capital markets, but also because of the focus on the investment behavior of small, credit constrained firms in studies of business cycles and economic growth. Since a significant fraction of these firms' investment is in used capital, it is important to consider capital reallocation as well as net new investment in explaining aggregate investment dynamics. Moreover, studying used capital markets may improve our understanding of the reversibility of investment decisions, which has received considerable attention in the literature. ${ }^{5}$

The composition of investment between new and used capital may also be affected by considerations besides financial constraints, such as the firm's need to be able to reverse investment decisions, technological differences across firms, or differences in taxation. We find that the relationship between the measures of financial constraints, including size, and used capital expenditures is robust to including control variables related to these alternative explanations. Once these controls are included, the explanatory power of firm size can be argued to be due to the ability of firm size to proxy for financial constraints.

Differences in factor prices may also give rise to variation in firms' decisions to invest in new vs. used capital. Bond (1983) develops a model with exogenous heterogeneity in factor prices where firms or sectors with low capacity utilization and low labor costs but high capital costs choose used capital since low labor costs and capacity utilization rates are complementary with the associated production downtime. Variation in factor prices is

\footnotetext{
${ }^{2}$ Becker, Haltiwanger, Jarmin, Klimek, and Wilson (2006) also use this data set and discuss its characteristics and the issues involved in measuring capital stocks and flows using this data.

${ }^{3}$ See Bond (1983) for similar evidence on used truck tractors.

${ }^{4}$ Oi (1983) discusses related evidence that smaller firms buy more used capital goods.

${ }^{5}$ See, e.g., Abel and Eberly $(1994,1996)$.
} 
not correlated with how quickly machines can be fixed, or with productivity in maintaining them. In contrast to our paper, the focus in Bond's model, which is static, is on the relative magnitude of maintenance costs, not on the timing of such payments. Relatedly, Michelacci and Quadrini (2005) and Garmaise (2006) provide models and evidence which suggests that small, financially constrained firms may initially pay low wages as a way to borrow from workers. These papers provide complementary support for the argument that firms use operating decisions, and not just capital structure decisions, to relax financial constraints. On the other hand, factor price variation has been used to understand trade in used capital across countries, where variation in such prices may be considerable, by Sen (1962) and Smith (1976).

Our work is also related to studies of vintage capital, durable goods, and the effects of credit constraints on investment. In standard vintage capital models the choice between new and used capital is determined by preferences for different vintages. Similarly, the choice between high and low quality durables is often modeled using exogenous preferences for quality. The results in this paper shed light on how these preferences over new and used capital, or goods of high and low quality, might be determined by underlying constraints on the investment decision, and hence complements these studies. ${ }^{6}$ Moreover, our paper is related to studies of the effects of credit constraints on investment decisions. ${ }^{7}$ Our results imply that the degree of a firm's credit constraints can be identified through revealed preference in the choice between new and used capital. This is important because although shifts in investment opportunities drive total capital expenditures, it is not clear that they should affect the new vs. used composition of such expenditures.

Finally, this paper is in part motivated by previous work on capital reallocation by

\footnotetext{
${ }^{6}$ For vintage capital models, see Benhabib and Rustichini (1991), Cooley, Greenwood, and Yorukoglu (1997), Campbell (1998), and Jovanovic (1998). For models of durable goods markets with exogenous preferences over quality, see, for example, Hendel and Lizzeri (1999) for a dynamic adverse selection model with sorting of new and used goods to heterogeneous consumers, Stolyarov (2002) for a model where goods deteriorate with age and volume varies with vintage, and Berkovec (1985), Porter and Sattler (1999), and Adda and Cooper (2000) for simulated discrete choice models and associated empirical tests in the automobile market.

${ }^{7}$ For a survey, see Hubbard (1998). For empirical tests of constrained and unconstrained firms' investment Euler equations, see Whited (1992) and Bond and Meghir (1994). For models describing the effects of variation in net worth on credit constraints, see Townsend (1979), Gale and Hellwig (1985), and Bernanke and Gertler (1989). For evidence that leverage affects overall investment in the trucking industry, see Zingales (1998). For evidence that borrowing constraints affect investment in entrepreneurial firms see Cagetti and De Nardi (2006). For models and evidence of distortions in durable goods consumption from credit constraints, see, for example, Chah, Ramey, and Starr (1995) and Campbell and Hercowitz (2003). Finally, for a general model of investment with a wedge between the purchase price and sale price of capital in the absence of credit constraints see Abel and Eberly (1994).
} 
Eisfeldt and Rampini (2006), who find that capital reallocation is procyclical while the benefits of reallocation, in terms of measures of cross sectional dispersion of productivity, seem countercyclical and conclude that the reallocation frictions must be higher in bad times. Could this be explained by the fact that firms are more credit constrained in bad times? This is not clear since while that would make it harder for potential buyers to buy used capital it might at the same time make potential sellers more eager to sell since they too are more credit constrained. ${ }^{8}$ Thus, one might ask: Who buys used capital? Here we study this question and provide both a theory and evidence that it is the more credit constrained firms who buy used capital. This may then be part of the explanation why there is less capital reallocation in bad times. ${ }^{9}$

The paper is organized as follows: Section 2 describes the model and the equilibrium in the used capital market, Section 3 discusses the empirical evidence, and Section 4 concludes.

\section{Credit Constraints and Investment in Used Capital}

This section describes the model and the equilibrium in the used capital market.

\subsection{The Environment}

Consider an economy with overlapping generations. Time is discrete and indexed by $t=0,1,2, \ldots$. At each time $t$, a generation with a continuum of agents with measure one is born. Generations live for one period, that is, for two dates. Agents have identical preferences and access to the same productive technologies, but differ in the idiosyncratic endowment of consumption goods, or internal funds, that they are born with. The preferences of an agent born in generation $t$ are $u\left(c_{t}\right)+\beta u\left(c_{t+1}\right)$, where $u$ is strictly increasing and concave and satisfies $\lim _{c \rightarrow 0} u^{\prime}(c)=+\infty .{ }^{10}$ At time $t$, each agent observes his idiosyncratic endowment $e \in \mathcal{E} \subset \mathbb{R}_{+}$which is distributed independently and identically with density $\pi(e)$ on $\mathcal{E}$.

At time $t$, each young agent chooses how much to invest in new and used capital for use in production at time $t+1$. The price of new capital is normalized to 1 . Used capital,

\footnotetext{
${ }^{8}$ For evidence that financially constrained firms are more likely to sell assets see Pulvino (1998) and Ramey and Shapiro (2001).

${ }^{9}$ See also Eisfeldt (2004) and Eisfeldt and Rampini (2007a) for additional mechanisms which render reallocation frictions countercyclical.

${ }^{10}$ Strict concavity of the utility function is not necessary for our results as long as the production function is concave. Indeed, we could assume linear preferences, i.e., risk neutrality. This can be seen using the marginal rates of transformation instead of substitution as discount rates as we discuss below.
} 
on the other hand, can be bought at a price $p_{u}$, which will be determined in equilibrium. Used capital will turn out to be cheaper than new capital in terms of its purchase price, i.e., $p_{u}<1$, in equilibrium, but it requires maintenance one period after it is bought. That is, investment in a unit of used capital at time $t$ requires payments of $p_{u}$ at time $t$ and $m_{u}>0$ at time $t+1$. New and used capital are assumed to be perfect substitutes in production. Thus, an agent who invests $i_{u, t}$ in used capital and $i_{n, t}$ in new capital will have a total amount of capital $k_{t}=i_{u, t}+i_{n, t}$. Capital generates output of $f\left(k_{t}\right)=k_{t}^{\alpha}$, where $\alpha \in(0,1)$, at time $t+1$. Capital depreciates at a rate of $\delta$, such that the agent will have $k_{t+1}=(1-\delta) k_{t}$ units of capital at time $t+1$. The agent can sell the depreciated capital at time $t+1$ as used capital to agents from the next generation. Notice that both new and used capital are sold as used capital after use in production. The idea is that except for the original owner who buys capital new, capital requires maintenance one period after the capital is purchased. Once capital has been previously owned, it is used and it does not matter how many previous owners there were. Notice that our model is consistent with the common perception that the difference between the purchase price and the sale price for new capital is larger than for used capital. Specifically, a unit of new capital is bought at a price of 1 and sold for $p_{u}(1-\delta)$ whereas a unit of used capital is bought for $p_{u}$ and sold for $p_{u}(1-\delta)$. However, this does not imply that the user cost of new capital is necessarily higher than the user cost of used capital since used capital requires maintenance whereas new capital does not.

Furthermore, an agent can borrow or save at a rate of return $R=\beta^{-1}$, which we fix exogenously to focus on the equilibrium in the used capital market. ${ }^{11}$ An agent can however only borrow against a fraction $0 \leq \theta \leq 1$ of the resale value of capital and can not borrow against future output. Thus, the agent needs to provide collateral for loans he takes out and the extent of collateralization is limited. This constraint can be motivated by assuming that lenders can only seize a fraction $\theta$ of the capital in case of default, which limits how much the agent can credibly promise to repay to that amount. ${ }^{12}$ This defines the credit constraint considered here. Agents' investment in used or new capital is constrained by the amount of their initial endowment of internal funds and their limited ability to borrow. Note that $\theta=0$ is a special case of our model where agents can not borrow at all, neither against output nor against capital. All the results that we obtain in this paper apply to this special case as well.

\footnotetext{
${ }^{11}$ We could instead determine the interest rate $R$ endogenously such that both the used capital market and the credit market clear without affecting our qualitative results. The discount rate of unconstrained agents would then be one over the equilibrium interest rate $1 / R$ rather than $\beta$.

${ }^{12}$ Kiyotaki and Moore (1997) consider a similar constraint. While we consider secured lending only, Eisfeldt and Rampini (2007b) consider the choice between secured lending and leasing (or renting) capital.
} 
We consider a stationary equilibrium where the price of used capital $p_{u}$ is determined such that all the used capital sold by agents in generation $t$ is bought by agents in generation $t+1$. The equilibrium will be stationary in the sense that all aggregate quantities, such as investment, the capital stock, and the volume of trade in used capital are constant across periods (see Section 2.3 for a formal definition).

\subsection{The Agent's Problem}

Consider the problem of an agent in generation $t, t \in\{0,1,2, \ldots\}$. Since we are studying a stationary model and all generations are identical, we will consider the problem of generation 0 to simplify notation. Taking the price of used capital $p_{u}$ as given, the agent's problem is one of maximizing utility by choice of consumptions $\left\{c_{0}, c_{1}\right\}$, investment in used capital $i_{u}$ and new capital $i_{n}$, and borrowing $b$, given their initial endowment of internal funds $e$. Specifically, the agent's problem is

$$
\max _{\left(c_{0}, c_{1}, i_{u}, i_{n}, b\right) \in \mathbb{R}_{+}^{4} \times \mathbb{R}} u\left(c_{0}\right)+\beta u\left(c_{1}\right)
$$

subject to

$$
\begin{aligned}
c_{0}+p_{u} i_{u}+i_{n} & \leq e+b \\
c_{1}+m_{u} i_{u}+R b & \leq k^{\alpha}+p_{u} k(1-\delta),
\end{aligned}
$$

where $k \equiv i_{u}+i_{n}$, and

$$
R b \leq \theta p_{u} k(1-\delta)
$$

Equations (1-2) are the budget constraints for time 0 and 1, with associated multipliers $\mu_{0}$ and $\mu_{1}$, respectively. Constraint (3) is the borrowing constraint which restricts borrowing to a fraction $\theta$ of the resale value of capital (in present value terms). Consumption lies in the interior of $\mathbb{R}_{+}^{2}$ since the utility function satisfies an Inada condition. The multiplier on the credit constraint is $\lambda_{b}$. When this constraint binds $\left(\lambda_{b}>0\right)$, we will say that the agent is credit constrained, and that the agent is more credit constrained the larger this

multiplier is. Moreover, one of the non-negativity constraints on investment in used and new capital, with associated multipliers $\lambda_{u}$ and $\lambda_{n}$, respectively, may bind (but not both since $\left.\lim _{k \rightarrow 0} f^{\prime}(k)=+\infty\right)$.

\subsection{Stationary Equilibrium}

An economy can be described by the agent's utility function and discount rate along with the technology parameters for the production function, depreciation, and the used capital 
maintenance cost, the collateralization rate, and the support and distribution over initial endowments of internal funds.

Definition 1 A stationary equilibrium for an economy $\left\{u(\cdot), \beta, \alpha, \delta, m_{u}, \theta, \mathcal{E}, \pi(e)\right\}$ is a used capital price $p_{u}$ and an allocation of consumptions $\left\{c_{0}^{*}(e), c_{1}^{*}(e)\right\}$, investments in new and used capital $\left\{i_{n}^{*}(e), i_{u}^{*}(e)\right\}$, and borrowing $\left\{b^{*}(e)\right\}$ for all $e \in \mathcal{E}$ such that:

(i) the allocation solves the problem of each agent in generation $t, \forall e \in \mathcal{E}, t$,

(ii) given the price of used capital $p_{u}$, the market for used capital clears $\forall t$ :

$$
\sum_{e \in \mathcal{E}} \pi(e) i_{n}^{*}(e)(1-\delta)+\sum_{e \in \mathcal{E}} \pi(e) i_{u}^{*}(e)(1-\delta)=\sum_{e \in \mathcal{E}} \pi(e) i_{u}^{*}(e)
$$

The right hand side of the market clearing condition in the above definition is the aggregate amount of used capital bought by each generation. The left hand side is the aggregate amount of capital sold by the previous generation, which is the sum of the aggregate amount of investment in new capital net of depreciation and the aggregate amount of investment in used capital net of depreciation.

If used capital were not cheap in terms of its purchase price, i.e., if $p_{u} \geq 1$, then all agents would buy new capital only, since new capital does not involve maintenance costs. However, if used capital were too cheap, specifically if the purchase price of used capital plus the maintenance costs discounted at $\beta$ were strictly less than the cost of buying new capital, i.e., if $p_{u}+\beta m_{u}<1$, then all agents would buy used capital and there would be no investment in new capital; thus:

Proposition 1 The price of used capital satisfies $1-\beta m_{u} \leq p_{u}<1$ in equilibrium.

The proofs of all propositions are in the appendix. The discount factor for time 1 payoffs of an agent who is not credit constrained is $\beta$ and the price of used capital in an economy without credit constraints would hence be $p_{u}=1-\beta m_{u}$. The price of used capital simply equals the price of new capital minus the discounted maintenance costs. The more interesting case, which we focus on, is the one in which $p_{u}>1-\beta m_{u}$, where credit constraints affect equilibrium prices. We provide conditions for this to be the case below.

\subsection{Characterization}

Here we characterize the solution to the agent's problem in an economy in which credit constraints affect pricing, i.e., in which $p_{u}>1-\beta m_{u}$. First, note that in such an economy, any agent who invests a positive amount in used capital must be credit constrained, i.e., the multiplier on that agent's credit constraint must be strictly positive: 
Proposition 2 Suppose $p_{u}>1-\beta m_{u}$. If $i_{u}(e)>0$, then $\lambda_{b}(e)>0$.

Thus, one can observe how credit constrained an agent in this economy is through revealed preference in their choice between new and used capital. ${ }^{13}$ This seems an interesting implication, since identifying credit constrained firms remains a challenge. ${ }^{14}$

Next, we characterize the solution to the agent's problem as a function of $e$, the endowment or internal funds of the agent. Agents with few internal funds invest in used capital. Indeed, agents with internal funds below a certain threshold $\bar{e}_{u}$ invest only in used capital. Agents with internal funds in an intermediate range, i.e., between $\bar{e}_{u}$ and $\bar{e}_{n}>\bar{e}_{u}$, invest in both new and used capital. Agents with internal funds above $\bar{e}_{n}$ invest in new capital only. Furthermore, the size of an agent's firm measured in units or value of capital is increasing in $e$. The size of an agent's firm is strictly increasing below $\bar{e}_{u}$, is constant between $\bar{e}_{u}$ and $\bar{e}_{n}$, and then strictly increasing again above $\bar{e}_{n}$ until internal funds reach $\overline{\bar{e}}>\bar{e}_{n}$. Agents with internal funds above $\overline{\bar{e}}$ are unconstrained and their level of investment, and hence the size of their firm, is constant and equal to the unconstrained optimal firm size. Thus, agents with few internal funds are credit constrained, start smaller firms, and invest in used capital. Figure 1 illustrates this characterization for a numerical example. The top left panel plots new and used capital investment and the middle left panel plots the fraction of investment comprised by used capital. The top right panel of Figure 1 plots borrowing. Agents with internal funds below $\overline{\bar{e}}$ borrow up to their borrowing capacity and borrowing is increasing in this range. Above $\overline{\bar{e}}$, borrowing is decreasing and agents with lots of internal funds save positive amounts. The multiplier on agents' borrowing constraints monotonically decreases with internal funds, and reaches zero for unconstrained agents, who borrow less than their borrowing capacity (see the middle right panel). The characterization is summarized in the next proposition: ${ }^{15}$

Proposition 3 Suppose $p_{u}>1-\beta m_{u}$. There exist cutoff levels of internal funds $\bar{e}_{u}<\bar{e}_{n}<\overline{\bar{e}}$ and levels of capital $\bar{k}<\overline{\bar{k}}$ such that the solution to the agent's problem satisfies:

\footnotetext{
${ }^{13}$ See Attanasio, Goldberg, and Kyriazidou (2005) for a related study of the decision to borrow in the auto loan market as a function of loan price and maturity for constrained and unconstrained consumers.

${ }^{14}$ See for example, Fazzari, Hubbard, and Petersen (1988), Kaplan and Zingales (1997), Lamont, Polk, and Saá-Réquejo (2001), and Whited and Wu (2006).

${ }^{15}$ There are effectively three ways to carry funds from time 0 to time 1 in this economy: (i) the concave production technology; (ii) saving at a rate of return $R=\beta^{-1}$; (iii) substituting new capital for used capital by investing $1-p_{u}$ at time 0 for a return of $m_{u}$, in terms of foregone maintenance costs, at time 1 , which implies a return of $m_{u} /\left(1-p_{u}\right)>\beta^{-1}$. Hence, agents first invest using the concave production technology, then substitute from used capital to new capital at a constant return of $m_{u} /\left(1-p_{u}\right)$, then invest in the concave production technology again, and finally save at the constant return $\beta^{-1}$.
} 
(i) For $e \leq \bar{e}_{u}, i_{u}>0, i_{n}=0$, and $b=\beta \theta p_{u} i_{u}(1-\delta)$. Moreover, $\frac{d i_{u}}{d e}>0$.

(ii) For $\bar{e}_{u}<e<\bar{e}_{n}, i_{u}>0, i_{n}>0$, and $b=\beta \theta p_{u}\left(i_{u}+i_{n}\right)(1-\delta)$. Moreover, $i_{u}+i_{n}=\bar{k}$, $\frac{d i_{u}}{d e}<0$, and $\frac{d i_{n}}{d e}>0$.

(iii) For $\bar{e}_{n} \leq e \leq \overline{\bar{e}}, i_{n}>0, i_{u}=0$, and $b=\beta \theta p_{u} i_{n}(1-\delta)$. Moreover, $\frac{d i_{n}}{d e}>0$.

(iv) For $e>\overline{\bar{e}}, i_{n}>0, i_{u}=0$, and $b<\beta \theta p_{u} i_{n}(1-\delta)$. Moreover, $i_{n}=\overline{\bar{k}}$.

Since used and new capital are assumed to be perfect substitutes in production the benefits from investing in used and new capital, respectively, in terms of output, resale value of capital, and shadow value of collateral are the same. In contrast, the cost of investing in new capital is 1 and the cost of investing in used capital is $p_{u}$ at time 0 and $m_{u}$ at time 1 . Using the agent's marginal rate of substitution to value the used capital cash outflows, the shadow price of used capital is

$$
p_{u}+\left[\beta \frac{u^{\prime}\left(c_{1}(e)\right)}{u^{\prime}\left(c_{0}(e)\right)}\right] m_{u} .
$$

The shadow price, or user cost, of used capital is thus agent specific and depends on the agent's endowment since the multiplier on the borrowing constraint drives a wedge between the valuations of agents with differing levels of internal funds. ${ }^{16}$

From the vantage point of agents with internal funds less than $\bar{e}_{u}$ used capital is relatively cheap, i.e., the shadow price of used capital is strictly less than 1. Agents with internal funds between $\bar{e}_{u}$ and $\bar{e}_{n}$ are indifferent between used and new capital at the margin since the shadow price of used capital equals the shadow price of new capital for them. Agents with internal funds exceeding $\bar{e}_{n}$ consider new capital relatively cheaper than used capital; in fact, the shadow price of used capital exceeds 1 for them. The bottom left panel of Figure 1 illustrates this by plotting the shadow prices for used capital which increases with the level of internal funds and the shadow price of new capital equals one.

New and used capital can also be valued for agents in each of the three endowment regions using the appropriate marginal rates of transformation. ${ }^{17}$ This also shows that with concave production technologies, even risk neutral agents would pay a premium for used capital if they were credit constrained and thus entrepreneurial risk aversion is not essential for our results. The marginal rates of transformation are

$$
\frac{p_{u}(1-\beta \theta(1-\delta))}{f^{\prime}(k(e))+p_{u}(1-\delta)(1-\theta)-m_{u}} \quad \text { and } \quad \frac{1-\beta \theta p_{u}(1-\delta)}{f^{\prime}(k(e))+p_{u}(1-\delta)(1-\theta)}
$$

\footnotetext{
${ }^{16}$ This is related to the result in the literature studying investment with financing constraints which shows that constrained firms make investment decisions which reflect the higher discount rate induced by binding credit constraints. See, e.g., Whited (1992) and Bond and Meghir (1994).

${ }^{17}$ Marginal rates of transformation are used to value assets in production based asset pricing following Cochrane (1991, 1996), including Restoy and Rockinger (1994) and Gomes, Yaron, and Zhang (2006).
} 
for investment in used and new capital, respectively. ${ }^{18}$ Since total investment is increasing in initial endowment, the discount factor is decreasing.

Two equilibrium pricing implications are notable: First, used capital is made expensive to unconstrained investors by the fact that it provides a convenience yield to constrained investors by relaxing their credit constraints and this makes these agents willing to pay more for used capital. Second, the premium at which used capital trades means that unconstrained agents invest more in equilibrium because they can sell capital at a premium in the used capital market.

\subsection{Conditions for Credit Constraints to Affect Pricing}

To determine the conditions for credit constraints to have pricing effects, we first briefly describe the properties of an economy where credit constraints do not affect prices, i.e., where $p_{u}=1-\beta m_{u}$. The characterization is quite similar to the one in an economy where credit constraints affect pricing. ${ }^{19}$ In particular, agents with few internal funds are credit constrained, buy only used capital, and start smaller firms. Investment in new capital is not uniquely determined for all agents, since unconstrained agents are indifferent between new and used capital at the margin, but the minimum (maximum) amount an agent is willing to invest in used (new) capital, $i_{u}^{\min }\left(i_{n}^{\max }\right)$, is uniquely determined and has the same properties as before. The maximum aggregate amount of new capital sold after one period given $p_{u}=1-\beta m_{u}$ is $\sum_{e \in \mathcal{E}} \pi(e) i_{n}^{\max }(e)(1-\delta)$ while the minimum aggregate net amount of used capital investment given $p_{u}=1-\beta m_{u}$ is $\sum_{e \in \mathcal{E}} \pi(e) i_{u}^{\min }(e) \delta$. Note that neither of these expressions involves equilibrium objects. Market clearing requires that $\sum_{e \in \mathcal{E}} \pi(e) i_{n}^{*}(e)(1-\delta)=\sum_{e \in \mathcal{E}} \pi(e) i_{u}^{*}(e) \delta$. Thus, if

\section{Condition $1 \quad \sum_{e \in \mathcal{E}} \pi(e) i_{n}^{\max }(e)(1-\delta)<\sum_{e \in \mathcal{E}} \pi(e) i_{u}^{\min }(e) \delta$,}

then unconstrained agents are not willing to invest enough in new capital to satisfy the net demand for used capital. This means that some constrained agents need to invest in new capital and hence the marginal agent pricing used capital is constrained. Under this condition, which essentially requires that there are sufficiently many agents with low internal funds, credit constraints affect pricing in equilibrium. The implication is that

\footnotetext{
${ }^{18}$ These are the marginal rates of transformation for internal funds. For example, an extra unit of used capital costs $p_{u}$, but allows extra borrowing of $\beta \theta p_{u}(1-\delta)$, and thus costs $p_{u}(1-\beta \theta(1-\delta))$ in internal funds (see the numerator). The return on used capital is $f^{\prime}(k)$ in terms of output, $p_{u}(1-\delta)(1-\theta)$ in terms of resale value net of loan repayment, and requires a maintenance payment of $m_{u}$ (see the denominator). The marginal rate of transformation for new capital has a similar interpretation.

${ }^{19}$ An appendix with an explicit characterization is available online.
} 
used capital should trade at a higher premium in countries (or industries) with more firms with low amounts of internal funds.

\section{Evidence on Investment in New and Used Capital}

Our model predicts that firms with less internal funds are credit constrained, invest more in used capital, and operate smaller firms. The empirical predictions in terms of financial variables are summarized below. We first focus on the prediction that the fraction of investment comprised by used capital and firm size are negatively related and find evidence that used to total capital expenditures are strongly decreasing with firm size. The stylized fact that small firms invest much more in used capital is very robust and, to the best of our knowledge, new. We acknowledge, however, that while financially constrained firms are likely to operate at a smaller scale than would be optimal in the absence of financial constraints, size is also affected by purely technological factors. Thus, we provide direct evidence on the link between the fraction of investment in used capital and measures of financial constraints suggested by our model and previous empirical studies. We find that firms which seem more financially constrained invest more in used capital. Finally, we study the robustness of the financial measures of credit constraints to alternative explanations for the relationship between size and investment in used capital. We add controls consistent with the following three alternative explanations: First, there is likely to be a smaller difference between the purchase and resale price of used capital, and this might make it attractive to firms which value its reversibility. ${ }^{20}$ Second, firms facing higher tax rates might favor new capital. Third, new capital might be complementary to other factors of production, such as a skilled workforce. ${ }^{21}$ We find that the relationship between used to total capital expenditures and measures of financial constraints is largely unaffected by adding these controls.

\footnotetext{
${ }^{20}$ The wedge between the purchase and resale price of used capital is smaller than that of new capital in our model, where both new and used capital are sold for $p_{u}$ after use in production, however there is no variation in the value of reversibility. See Abel and Eberly (1994) for the effects of partial reversibility on investment decisions. See Ramey and Shapiro (1998) for a model where markets for used capital are thin due to capital specificity and a search and matching friction.

${ }^{21}$ See Oi (1983) for a similar argument and some evidence, and Jovanovic (1998) for a model of vintage capital where skilled labor and the newest vintage are complements.
} 


\subsection{Empirical Predictions}

The model predicts that the fraction of used capital expenditures decreases with internal funds and that capital increases with internal funds. The empirical implication is that used capital expenditures should be negatively related to measures of internal funds, e.g., cash (to assets) and cash flow (to assets), and positively related to debt (to assets) to the extent that outstanding debt reduces available internal funds. Moreover, the relationship to the size of the firm should be negative. In the model, we did not explicitly define dividends. But consider the maximal additional time 0 dividend that could be paid to the agent, who would in turn lend these funds out to keep his consumption unchanged, defined as $d_{0} \equiv \beta \theta p_{u} k(1-\delta)-b$. Such dividends could only be paid when the borrowing constraint does not bind, and hence used capital expenditures and dividends (to assets) are negatively related. Finally, define Tobin's $q$ as $q \equiv \frac{\beta\left(k^{\alpha}+p_{u} k(1-\delta)-m_{u} i_{u}\right)}{i_{n}+p_{u} i_{u}}$, which is the present value of the reservation payments (per unit of capital) required for an agent to give up production and all capital while keeping his consumption profile unchanged. Due to the concavity of the production function, Tobin's $q$ is decreasing in internal funds and hence size. To sum up:

Prediction 1 The fraction of used capital expenditures:

(i) decreases with available internal funds, and hence decreases with cash and cash flow (to assets) and increases with outstanding debt (to assets),

(ii) decreases with firm size,

(iii) decreases with dividends (to assets),

(iv) increases with Tobin's q.

\subsection{Data}

We use two main data sources for estimates of used capital expenditures, the Vehicle Inventory and Use Survey (VIUS) and the Annual Capital Expenditure Survey (ACES), both by the U.S. Census Bureau. ${ }^{22}$

The Vehicle Inventory and Use Survey (VIUS) is a survey of the truck population in the U.S. and provides information about the physical and operational characteristics of trucks. We use the publicly available micro data file of the 1997 VIUS. The observation unit in this survey is a truck. The survey asks whether a truck was purchased new or used, what the size is of the fleet that the truck is a part of, and whether the truck was used for business use. We use data on trucks dedicated to business use only.

\footnotetext{
${ }^{22}$ The VIUS and ACES reports and related information are available at http://www.census.gov/.
} 
The Annual Capital Expenditure Survey (ACES) is a comprehensive survey of capital investment by nonfarm businesses covering all sectors. We use both data from the public ACES reports and confidential ACES micro data. We are among the first researchers to use the confidential ACES micro data. The survey asks firms to report their capital expenditures on new capital and used capital, where used capital is defined as "buildings and other structures which have been previously owned and occupied, machinery and secondhand equipment, and other used depreciable assets." The cost of land is excluded. Based on the 1998 ACES report, the main types of used structures expenditures are on commercial buildings, offices, residential buildings, and hotels and motels. The most important used equipment expenditures are on transportation equipment, industrial equipment, miscellaneous equipment, and information processing equipment. Moreover, there is considerable cross industry variation in the importance of used capital. ${ }^{23}$

\subsection{Evidence on Used Capital Investment and Size}

We first provide evidence on the choice between new and used trucks as a function of the size of the fleet using data from the 1997 VIUS for trucks dedicated to business use. Trucks are an interesting asset to study because there is a large market for used trucks. Overall, about $50 \%$ of trucks were purchased used. This fraction decreases monotonically with fleet size. For example, businesses with fleets of 10 to 24 purchased about $38 \%$ of their trucks used, whereas businesses with fleets of 100 to 499 vehicles purchased only about $24 \%$ of their trucks used. Figure 2 displays the strong relationship between the fraction of trucks purchased used and size for both trucks overall and for different body types. Controlling for body type alleviates the concern that fleet size might be correlated with how specialized the trucks are. Businesses with the smallest fleets buy at least $40 \%$ of trucks of all body types used, while businesses with the largest fleets buy no more than $37 \%$ of trucks of any body type used.

Next we provide evidence on the composition of capital expenditures on new vs. used capital for firms of different sizes. Starting with the full sample of the ACES micro data, we exclude firms with zero assets and document the fraction of capital expenditures comprised by used capital for size deciles defined by beginning of year assets, employees, and sales. Table 1 presents the average ratio of used capital expenditures to total capital expenditures across firm size deciles using ACES micro data from 1993 to $2002 .{ }^{24}$ For overall capital expenditures, investment in used capital decreases by size for all three measures of size. Used capital comprises $28 \%$ of capital expenditures for firms in the

\footnotetext{
${ }^{23}$ Industry level data are available in the ACES Reports published by the U.S. Census Bureau.

${ }^{24}$ Details of the data construction are given in Table 1.
} 
lowest asset decile (with assets below $\$ 0.10$ million) and $10 \%$ for firms in the highest asset decile (with assets exceeding $\$ 186.55$ million) and this fraction decreases monotonically across asset deciles. For deciles defined by beginning of year assets, we also report data for structures and equipment separately and for both asset classes the fraction of expenditures comprised by used capital decreases monotonically in size. The fact that the relationship between size and investment holds within asset classes suggests that this relationship is not due to a compositional effect between structures and equipment for firms of different sizes. Figure 3 clearly illustrates the relationship between size (measured in terms of assets) and used capital expenditures for capital overall, and equipment and structures separately. Thus, we conclude that small firms invest more in used capital than large firms.

The relationship between size and used capital expenditures is robust and can be documented for a large universe of firms, including firms which are not public and for which financial data is unavailable. In our model small firms are constrained and have a larger multiplier on their borrowing constraint. The effect of credit constraints is manifested in the composition of investment in terms of new and used capital and in firm size. ${ }^{25}$

\subsection{Evidence on Used Capital Investment and Credit Constraints}

This section provides direct evidence on the link between the fraction of capital expenditures on used capital and measures of financial constraints. To study the relationship between used capital expenditures and financial variables we merge the ACES data with data from Compustat using a Census-Compustat bridge file. We restrict the data to the 1998 ACES since that year is a detailed survey year and the data quality is likely higher. Moreover, the annual panel rotation limits the extent to which the panel dimension of the data can be exploited. We use the ACES micro data for the fraction of capital expenditures on used capital and data from Compustat for the financial variables.

We report the relationship between used capital expenditures and measures of the degree of credit constraints at the firm level. Our measures of constraints are motivated by our model as well as empirical studies such as Kaplan and Zingales (1997) and Whited and $\mathrm{Wu}$ (2006). Table 2 uses these measures of financial constraints to compare conditional means of used capital expenditures for firms which appear more vs. less constrained. We report two measures of the fraction of capital expenditures on used capital. The first measure, in Panel A, is the deviation of the firm level fraction of capital expenditures on used capital from the industry mean of this ratio. There is substantial variation in

\footnotetext{
${ }^{25}$ Classic models of borrowing constraints also link internal funds to the degree of financial constraints. See, for example, Townsend (1979), Gale and Hellwig (1985), and Bernanke and Gertler (1989).
} 
the size of the used capital market across industries, and using the deviation from the industry mean allows us to study the effect of the credit constraints variables conditional on industry. The second measure, in Panel B, reports the conditional means for firm level fractions without adjusting for industry means. We report used capital expenditures for the smallest and largest size quartiles, where size is defined by assets, sales, or employees, and find that by all measures, a larger fraction of small firms' capital expenditures are comprised by used capital. Similarly, by both measures of used capital expenditures, firms that are in the most constrained quartile as defined by either the Kaplan and Zingales (1997) or the Whited and Wu (2006) credit constraints indices invest more in used capital than do firms in the least constrained quartiles. Firms which do not pay dividends choose to invest a larger fraction in used capital than do firms which pay dividends. Finally, firms which have a below investment grade credit rating invest more in used capital than do firms which are rated investment grade. ${ }^{26}$

In order to condition on multiple variables simultaneously, Table 4 reports the results of cross-sectional regressions using data on overall capital expenditures for 1998 . We provide estimates from regressions of the fraction of capital expenditures on used capital on the financial variables suggested by our model, an intercept, and industry dummies. ${ }^{27}$ We first provide regressions of used to total capital expenditures on each of these financial variables controlling for size and industry dummies. Since some of our financial constraints variables may be correlated with size, these bivariate regressions illustrate the independent effect of the financial variables. We also report results for a multivariate regression with all financial constraints variables, again controlling for industry at the three digit level. The details of the variables used and descriptive statistics are in Table 3.

Overall, the estimates suggest that there is a significant relationship with the predicted sign between the fraction of capital expenditures on used capital and the financial variables. When each of the financial variables is included separately, all variables except cash flow to assets have the predicted relationship with used to total capital expenditures. Moreover, all variables except this cash flow measure and Tobin's $q$ are significant at the $5 \%$ level. $^{28}$ These regressions show that the fraction of capital expenditures on used capital is significantly higher for smaller firms, for firms which pay lower dividends

\footnotetext{
${ }^{26}$ The fact that both industry deviations are negative implies that firms that are not rated invest even more in used capital than firms with low ratings.

${ }^{27}$ Relatedly, Kaplan and Zingales (1997) use qualitative information in SEC filings to rank firms' financial constraints and show that firms which indicate high levels of constraints are smaller, pay lower dividends relative to assets, have higher debt to assets, lower cash flow to assets, higher Tobin's $q$, and lower cash to assets.

${ }^{28}$ See Erickson and Whited (2005) and papers cited therein for a detailed description of the effects of measurement error in Tobin's $q$.
} 
(relative to assets), for firms with more long-term debt (relative to assets), and for firms with less cash (relative to assets). Thus, the financial variables contain additional information relative to size alone. When all variables are included simultaneously, the sign on all financial measures of constraints remains unchanged. The sign and significance of size is unchanged. Long term debt to assets and Tobin's $q$ gain in significance, while the significance of dividends to assets and cash to assets declines. This is to be expected since these variables are likely to capture some of the same information. Moreover, all our significant estimates have the same sign as those found by Kaplan and Zingales (1997) in their estimation of an ordered logit which relates a qualitative measure of financial constraints to these financial variables. The estimates are also economically important since a one standard deviation change in any of the significant independent variables changes the fraction of used capital expenditures by $1-2 \%$, which is considerable given the mean of $12 \%$.

Notice that when we use the merged ACES-Compustat data we use data for relatively large firms since Compustat firms are publicly held. In terms of the asset deciles from Table 1 we are hence likely only using data for the top few deciles where there is relatively little variation in the average fraction of capital expenditures on used capital (which varies between about $13 \%$ and $10 \%$ in the top 4 deciles for example). Indeed, the mean of the fraction of capital expenditures on used capital is $12 \%$ in the merged data (see Table 3) which equals the value in the eighth decile. Moreover, more than $50 \%$ of the observations in the merged sample must be in the top decile, since the median value of assets is over $\$ 650$ million (which is considerably above the bottom cutoff of the top decile). Nevertheless, we find a significant relationship between used capital expenditures and measures of financial constraints here. This suggests the following tip of the iceberg hypothesis: To the extent that we can extrapolate from our results using size as the proxy for financial constraints, smaller firms appear considerably financially constrained since the fraction of capital expenditures on used capital is much higher (up to 28\%) for smaller firms for which we do not have other measures of financial constraints.

To check the robustness of the relationship between used to total capital expenditures and measures of financial constraints, we also include in Table 4 results including controls suggested by three alternative explanations. First, we investigate whether firms which might value reversibility invest relatively more in used capital by including firm age and the standard deviation of sales growth over the last five years. We find neither variable to be significant when size and the measures of financial constraints are included in the regression. Moreover, the coefficients on size and long term debt are unaffected by these additional controls. The main effect on the coefficients on the financial variables is that 
$q$ loses significance. Next, we investigate whether firms which face higher tax rates invest relatively less in used capital using firms' before financing marginal tax rates. ${ }^{29}$ We do not think there is a clear cut expected sign for the tax rate, since both depreciation (which might be higher for new capital) and maintenance (which we argue is higher for used capital) are expenses which can be deducted from taxable income. Indeed the coefficient on the marginal tax rate is insignificant, and in fact the inclusion of this variable increases the magnitude of the coefficients on size and long term debt, and increases the significance of Tobin's $q$.

Finally, we include variables intended to capture the potential complementarity between skilled labor and/or specialized assets in place, and new capital. We include in our regression the ratio of property, plant and equipment to employees to capture the capital labor ratio with the idea that firms with skilled labor have higher capital to labor ratios. We include the ratio of $R \& D$ to sales to capture the idea that firms with specialized assets in place are likely to spend more on $R \& D$. We also add the ratio of sales to employees to capture the idea that firms with more skilled labor should have more sales per employee. We find that none of these variables are significant except for sales to employees, which has a negative coefficient which is significant at the $10 \%$ level. Although this is consistent with a complementarity between new capital and skilled labor, it is also consistent with the idea that constrained firms might have lower sales to employees. Finally, while size may be affected by technological considerations, we argue that, when controlling for these technological factors, the remaining explanatory power of size may reflect the effect of financial constraints.

We report results for structures and equipment separately as well, to check that the results for overall capital expenditures are not due to variation in the composition of capital expenditures by type (see Table 5). We find similar results for both measures. In particular, for both structures and equipment, size and long term debt to assets have the most significant relationship with used to total capital expenditures of all the financial measures. The fact that the results are similar within asset classes suggests that the results for capital overall are not being driven by compositional effects. ${ }^{30}$

\subsection{Evidence for Consumers}

One can apply the same logic to individual consumers and households to understand used durable goods markets. Credit constrained households may buy used capital because the higher maintenance cost allow them to partially pay for it later on. Indeed, Aizcorbe

\footnotetext{
${ }^{29}$ This variable was provided to us by John Graham (see Graham, Lemmon, and Schallheim, 1998).

${ }^{30}$ The results are again robust to including control variables, but we do not report these here.
} 
and Starr-McCluer (1997) report evidence that households with lower income and lower financial assets buy a larger fraction of cars used. They use data from the Survey of Consumer Finances (SCF) and the Consumer Expenditure Interview Survey (CEX) for 1992 and find that households with income below $\$ 10,000$ (1992 dollars) buy $64.3 \%$ and $61.2 \%$ of cars used (in the SCF and the CEX, respectively), while households with income of $\$ 100,000$ or more buy $34.0 \%$ and $35.9 \%$ used. Similarly, households with financial assets below $\$ 500$ (1992 dollars) buy $77.3 \%$ and $79.9 \%$ used, while households with financial assets of $\$ 10,000$ or more buy $39.3 \%$ and $39.6 \%$ used.

Moreover, they report that households with lower income and lower financial assets also tend to buy used cars which are older. The data from the SCF and the CEX, respectively, report that the average age of used vehicles at the time of acquisition are 7.9 and 8.0 years for households with financial assets below $\$ 500$ (1992 dollars) and 5.2 and 6.4 years for households with financial assets of $\$ 10,000$ or more. By income, the SCF reports ages of 7.8 years for households with income below $\$ 10,000$ (1992 dollars) and 5.1 years for households with income of $\$ 100,000$ or more, while the CEX in contrast reports ages 6.8 years and 7.7 years, respectively. This would be consistent with an extension of our model where maintenance costs continue to increase with the age of the capital good, and hence a larger fraction of the user cost of older capital would occur in terms of maintenance rather than up front investment, which makes it attractive to credit constrained households.

\section{Conclusions}

This paper develops a model of the decision to invest in new vs. used capital when used capital has a lower purchase price, but requires maintenance payments later on. We find that used capital is valuable to credit constrained agents because it relaxes borrowing constraints. Used capital allows constrained agents to operate larger scale firms by deferring some of the capital costs. We find that agents with low levels of internal funds invest more in used capital, are credit constrained, and operate smaller scale firms. Financial constraints imply that discount factors are firm specific and used capital can thus seem cheap from the vantage point of a constrained firm while unconstrained firms consider it expensive. Importantly, the extent of firms' financial constraints can hence be measured by the composition of their capital expenditures.

We present evidence that used capital indeed comprises a much larger fraction of capital expenditures for small firms who are likely to face binding credit constraints. Moreover, the fraction of capital expenditures on used capital is significantly related to 
measures of financial constraints, with more constrained firms using a larger fraction of used capital. We document these facts for capital overall as well as for structures and equipment separately. The fact that small and credit constrained firms invest in relatively more used capital is important for understanding used capital markets. Our model implies that the fraction of credit constrained firms affects the premium at which used capital trades. Understanding who buys used capital, and why, is also important for studying capital reallocation and aggregate investment dynamics. Furthermore, since small, credit constrained firms have been argued to be particularly sensitive to aggregate fluctuations and central to understanding business cycles and growth, the market for used capital may be important for understanding this connection.

While we focus on the investment decision by firms, one can apply the same logic to individual consumers and households to understand used durable goods markets. More generally, our results shed light on the choice between capital vintages and consumer durables of different quality, which are typically motivated by exogenous variation in preferences for vintages or quality.

\section{Appendix}

Proof of Proposition 1. The objective of the agent's problem is concave and the constraint set convex and hence the first order conditions are necessary and sufficient. The first order conditions with respect to $i_{u}$ and $i_{n}$ are

$$
\begin{aligned}
\mu_{0} p_{u} & =\mu_{1}\left(\alpha k^{\alpha-1}+p_{u}(1-\delta)-m_{u}\right)+\lambda_{u}+\lambda_{b} \theta p_{u}(1-\delta) \\
\mu_{0} & =\mu_{1}\left(\alpha k^{\alpha-1}+p_{u}(1-\delta)\right)+\lambda_{n}+\lambda_{b} \theta p_{u}(1-\delta)
\end{aligned}
$$

and with respect to $b$ is $\mu_{0}=\mu_{1} \beta^{-1}+\lambda_{b} \beta^{-1}$, where $\mu_{t}$ is the multiplier on the date $t$ budget constraint $\left(\lambda_{b}, \lambda_{u}\right.$, and $\lambda_{n}$ are defined in the text). Subtracting (4) from (5) gives

$$
\mu_{0}\left(1-p_{u}\right)=\mu_{1} m_{u}+\lambda_{n}-\lambda_{u}
$$

Thus, if $p_{u} \geq 1$, then $\lambda_{u}>0$ (the strict inequality follows from the fact that $\mu_{1}>0$ ) and hence $i_{u}=0$ for all $e \in \mathcal{E}$, which is impossible in equilibrium. If $p_{u}<1-\beta m_{u}$, then using this inequality and (6), we have $\mu_{0} \beta m_{u}<\mu_{0}\left(1-p_{u}\right)=\mu_{1} m_{u}+\lambda_{n}-\lambda_{u}$ and substituting for $\mu_{0}$ using the first order condition with respect to $b$ we get $\lambda_{b} m_{u}<\lambda_{n}-\lambda_{u}$. Thus, $\lambda_{n}>0$ and hence $i_{n}=0$ for all $e \in \mathcal{E}$ which is again impossible in equilibrium.

Proof of Proposition 2. If $i_{u}>0, \lambda_{u}=0$. Equation (6) together with $p_{u}>1-\beta m_{u}$ and $\mu_{0}=\mu_{1} \beta^{-1}+\lambda_{b} \beta^{-1}$ imply that $\mu_{1} m_{u}+\lambda_{n}=\mu_{0}\left(1-p_{u}\right)<\mu_{0} \beta m_{u}=\mu_{1} m_{u}+\lambda_{b} m_{u}$ 
and thus $\lambda_{b}>0$.

Proof of Proposition 3. The objective is continuous and strictly concave and the constraint set is convex and continuous. By the theorem of the maximum (see, e.g., Stokey, Lucas, and Prescott, 1989), the maximizing choices are continuous in $e$.

First, suppose $i_{u}>0$. By Proposition $2, \lambda_{b}>0$, i.e., $b=\beta \theta p_{u}\left(i_{u}+i_{n}\right)(1-\delta)$. In the case where $i_{n}=0$, the first order condition with respect to $i_{u},(4)$, can be written as

$$
\begin{aligned}
u^{\prime}\left(e-p_{u} i_{u}(1-\beta \theta(1-\delta))\right) p_{u}(1-\beta \theta(1-\delta))= & \beta u^{\prime}\left(i_{u}^{\alpha}+p_{u} i_{u}(1-\delta)(1-\theta)-m_{u} i_{u}\right) \times \\
& \left(\alpha i_{u}^{\alpha-1}+p_{u}(1-\delta)(1-\theta)-m_{u}\right), \quad(7)
\end{aligned}
$$

using $\mu_{0}=\mu_{1} \beta^{-1}+\lambda_{b} \beta^{-1}$ to substitute for $\lambda_{b}$. Totally differentiating we get $\frac{d i_{u}}{d e}>0$.

Next, consider the case where both $i_{u}>0$ and $i_{n}>0$, such that the first order conditions with respect to $i_{u}$ and $i_{n}$ are, again substituting for $\lambda_{b}$,

$$
\begin{aligned}
& \mu_{0} p_{u}(1-\beta \theta(1-\delta))=\mu_{1}\left(\alpha k^{\alpha-1}+p_{u}(1-\delta)(1-\theta)-m_{u}\right) \\
& \mu_{0}\left(1-\beta \theta p_{u}(1-\delta)\right)=\mu_{1}\left(\alpha k^{\alpha-1}+p_{u}(1-\delta)(1-\theta)\right)
\end{aligned}
$$

Dividing (8) by (9) implies $\frac{p_{u}-\beta \theta p_{u}(1-\delta)}{1-\beta \theta p_{u}(1-\delta)}=1-\frac{m_{u}}{\alpha k^{\alpha-1}+p_{u}(1-\delta)(1-\theta)}$ which implicitly defines $\bar{k}$. Totally differentiating (9) implies that $\frac{d \mu_{0}}{d e}\left(1-\beta \theta p_{u}(1-\delta)\right)=\frac{d \mu_{1}}{d e}\left(\alpha \bar{k}^{\alpha-1}+p_{u}(1-\delta)(1-\theta)\right)$, i.e., $\frac{d \mu_{0}}{d e}$ and $\frac{d \mu_{1}}{d e}$, and hence $\frac{d c_{0}}{d e}$ and $\frac{d c_{1}}{d e}$, have the same sign. Totally differentiating the budget constraints gives $\frac{d c_{0}}{d e}=1-\left(1-p_{u}\right) \frac{d i_{n}}{d e}$ and $\frac{d c_{1}}{d e}=m_{u} \frac{d i_{n}}{d e}$ and thus $\frac{d i_{n}}{d e}=-\frac{d i_{u}}{d e}>0$. At the upper boundary of this region, the capital $\bar{k}$ is entirely made up by new capital. Equation (9) can then be written as

$$
\begin{aligned}
u^{\prime}\left(e-\bar{k}\left(1-\beta \theta p_{u}(1-\delta)\right)\right)\left(1-\beta \theta p_{u}(1-\delta)\right)= & \beta u^{\prime}\left(\bar{k}^{\alpha}+p_{u} \bar{k}(1-\delta)(1-\theta)\right) \times \\
& \left(\alpha \bar{k}^{\alpha-1}+p_{u}(1-\delta)(1-\theta)\right)
\end{aligned}
$$

which defines $\bar{e}_{n}$. At the lower boundary, the agent only invest in used capital and hence

$$
\begin{aligned}
u^{\prime}\left(e-p_{u} \bar{k}(1-\beta \theta(1-\delta))\right)\left(1-\beta \theta p_{u}(1-\delta)\right)= & \beta u^{\prime}\left(\bar{k}^{\alpha}+p_{u} \bar{k}(1-\delta)(1-\theta)-m_{u} \bar{k}\right) \times \\
& \left(\alpha \bar{k}^{\alpha-1}+p_{u}(1-\delta)(1-\theta)\right)
\end{aligned}
$$

which implicitly defines the lower bound on internal funds $\bar{e}_{u}$. Comparing (10) and (11) implies $u^{\prime}\left(\bar{e}_{u}-p_{u} \bar{k}(1-\beta \theta(1-\delta))\right)>u^{\prime}\left(\bar{e}_{n}-\bar{k}\left(1-\beta \theta p_{u}(1-\delta)\right)\right)$ and thus $\bar{e}_{u}<\bar{e}_{n}$.

Finally, suppose $i_{n}>0$ and $i_{u}=0$. In the case where $\lambda_{b}>0$, (9) can be written as

$$
\begin{aligned}
u^{\prime}\left(e-i_{n}\left(1-\beta \theta p_{u}(1-\delta)\right)\right)\left(1-\beta \theta p_{u}(1-\delta)\right)= & \beta u^{\prime}\left(i_{n}^{\alpha}+p_{u} i_{n}(1-\delta)(1-\theta)\right) \times \\
& \left(\alpha i_{n}^{\alpha-1}+p_{u}(1-\delta)(1-\theta)\right) .
\end{aligned}
$$


Totally differentiating we get $\frac{d i_{n}}{d e}>0$. In the case where $\lambda_{b}=0$, the agent is unconstrained, and we have $\mu_{0}=\beta^{-1} \mu_{1}$ and $c_{0}=c_{1}$. The first order condition with respect to $i_{n}$ simplifies to $1=\beta\left(\alpha k^{\alpha-1}+p_{u}(1-\delta)\right)$ which defines $\overline{\bar{k}}$. Equation (9) and the fact that $\mu_{0}<\mu_{1} \beta^{-1}$ at $\bar{k}$ imply that $\bar{k}<\overline{\bar{k}}$. At the lower boundary of this region, savings $b$ equal $\beta \theta p_{u} \bar{k}(1-\delta)$ and, since $c_{0}=c_{1}, e-\overline{\bar{k}}\left(1-\beta \theta p_{u}(1-\delta)\right)=\overline{\bar{k}}^{\alpha}+p_{u} \overline{\bar{k}}(1-\delta)(1-\theta)$ which defines $\overline{\bar{e}}$ and, comparing (10) and (12) evaluated at $\overline{\bar{k}}, \bar{e}_{n}<\overline{\bar{e}}$.

Since the maximizing choices are continuous functions, we conclude that the agent invests in used capital only below $\bar{e}_{u}$, in new and used capital between $\bar{e}_{u}$ and $\bar{e}_{n}$, and in new capital only above $\bar{e}_{n}$. Moreover, the agent is credit constrained below $\overline{\bar{e}}$ and unconstrained above that value.

\section{References}

Abel, A.B., Eberly, J.C., 1994. A unified model of investment under uncertainty. American Economic Review 84, 1369-1384.

Abel, A.B., Eberly, J.C., 1996. Optimal investment with costly reversibility. Review of Economic Studies 63, 581-593.

Adda, J., Cooper, R., 2000. The dynamics of car sales: A discrete choice approach. NBER Working Paper No. 7785.

Aizcorbe, A., Starr-McCluer, M., 1997. Vehicle ownership, purchases, and leasing: Consumer survey data. Monthly Labor Review 120, 34-40.

Attanasio, O.P., Goldberg, P.K., Kyriazidou, E., 2005. Credit constraints in the market for consumer durables: Evidence from micro data on car loans. Working paper, UCL, Columbia University, and UCLA.

Becker, R., Haltiwanger, J., Jarmin, R., Klimek, S., Wilson, D., 2006. Micro and macro data integration: The case of capital. In: Jorgensen, D., Landefeld, S., Nordhaus, W. (Eds.), A New Architecture for the National Accounts, University of Chicago Press, Chicago.

Benhabib, J., Rustichini, A., 1991. Vintage capital, investment and growth. Journal of Economic Theory 55, 323-339.

Berkovec, J., 1985. New car sales and used car stocks: A model of the automobile market. RAND Journal of Economics 16, 195-214.

Bernanke, B., Gertler, M., 1989. Agency costs, net worth, and business fluctuations. American Economic Review 79, 14-31.

Bond, E.W., 1982. A direct test of the "lemons" model: The market for used pickup trucks. American Economic Review 72, 836-840.

Bond, E.W., 1983. Trade in used equipment with heterogeneous firms. Journal of Political Economy 91, 688-705.

Bond, S., Meghir, C., 1994. Dynamic investment models and the firm's financial policy. Review of Economic Studies 61, 197-222. 
Cagetti, M., De Nardi, M., 2006. Entrepreneurship, frictions, and wealth. Journal of Political Economy 114, 835-870.

Campbell, J.R., 1998. Entry, exit, embodied technology, and business cycles. Review of Economic Dynamics 1, 371-408.

Campbell, J.R., Hercowitz, Z., 2003. The dynamics of work and debt. NBER Working Paper No. 10201.

Chah, E.Y., Ramey, V.A., Starr, R.A., 1995. Liquidity constraints and intertemporal consumer optimization: Theory and evidence from durable goods. Journal of Money, Credit and Banking 27, 272-287.

Cochrane, J.H., 1991. Production-based asset pricing and the link between stock returns and economic fluctuations. Journal of Finance 46, 209-237.

Cochrane, J.H., 1996. A cross-sectional test of an investment-based asset pricing model. Journal of Political Economy 104, 572-621.

Cooley, T.F., Greenwood, J., Yorukoglu, M., 1997. The replacement problem. Journal of Monetary Economics 40, 457-499.

Eisfeldt, A.L., 2004. Endogenous liquidity in asset markets. Journal of Finance 59, 1-30.

Eisfeldt, A.L., Rampini, A.A., 2006. Capital reallocation and liquidity. Journal of Monetary Economics 53, 369-399.

Eisfeldt, A.L., Rampini, A.A., 2007a. Managerial incentives, capital reallocation, and the business cycle. Journal of Financial Economics, forthcoming.

Eisfeldt, A.L., Rampini, A.A., 2007b. Leasing, ability to repossess, and debt capacity. Working paper, Northwestern University and Duke University.

Erickson, T., Whited, T.M., 2005. Investment-cash flow sensitivity and proxy-quality thresholds. Working paper, Bureau of Labor Statistics and University of Wisconsin.

Fazzari, S.M., Hubbard, R.G., Petersen, B.C., 1988. Financing constraints and corporate investment. Brookings Papers on Economic Activity 1, 141-195.

Garmaise, M.J., 2006. Production in entrepreneurial firms: The effects of financial constraints on labor and capital. Working paper, UCLA.

Gomes, J., Yaron, A., Zhang, L., 2006. Asset pricing implications of firms' financing constraints. Review of Financial Studies 19, 1321-1356.

Graham, J.R., Lemmon, M.L., Schallheim, J.S., 1998. Debt, leases, taxes, and the endogeneity of corporate tax status. Journal of Finance 53, 131-162.

Hendel, I., Lizzeri, A., 1999. Adverse selection in durable goods markets. American Economic Review 89, 1097-1115.

Hubbard, R.G., 1998. Capital-market imperfections and investment. Journal of Economic Literature 36, 193-225.

Jovanovic, B., 1998. Vintage capital and inequality. Review of Economic Dynamics 1, 497-530.

Kaplan, S.N., Zingales, L., 1997. Do investment-cash flow sensitivities provide useful measures of financing constraints? Quarterly Journal of Economics 112, 169-215.

Kiyotaki, N., Moore, J., 1997. Credit cycles. Journal of Political Economy 105, 211-248. 
Lamont, O., Polk, C., Saá-Réquejo, J., 2001. Financial constraints and stock returns. Review of Financial Studies 14, 529-554.

McGrattan, E.R., Schmitz, Jr., J.A., 1999. Maintenance and repair: Too big to ignore. Federal Reserve Bank of Minneapolis Quarterly Review 23 (4), 2-13.

Michelacci, C., Quadrini, V., 2005. Financial markets and wages. NBER Working Paper No. 11050.

Oi, W.Y., 1983. Heterogeneous firms and the organization of production. Economic Inquiry 21, 147-171.

Porter, R.H., Sattler, P., 1999. Patterns of trade in the market for used durables: Theory and evidence. NBER Working Paper No. 7149.

Pulvino, T.C., 1998. Do asset fire sales exist? An empirical investigation of commercial aircraft transactions. Journal of Finance 53, 939-978.

Ramey, V.A., Shapiro, M.D., 1998. Displaced capital. NBER Working Paper No. 6775.

Ramey, V.A., Shapiro, M.D., 2001. Displaced capital. Journal of Political Economy 109, 958-992.

Restoy, F., Rockinger, G.M., 1994. On stock market returns and returns on investment. Journal of Finance 49, 543-556.

Sen, A.K., 1962. On the usefulness of used machines. Review of Economics and Statistics $44,346-48$.

Smith, M.A.M., 1976. International trade theory in vintage models. Review of Economic Studies 43, 99-113.

Stokey, N.L., Lucas, R.E., Prescott, E.C., 1989. Recursive Methods in Economic Dynamics. Harvard University Press, Cambridge.

Stolyarov, D., 2002. Turnover of used durables in a stationary equilibrium: Are older goods traded more? Journal of Political Economy 110, 1390-1413.

Zingales, L., 1998. Survival of the fittest or the fattest? Exit and financing in the trucking industry. Journal of Finance 53, 905-938.

Whited, T., 1992. Debt, liquidity constraints, and corporate investment: Evidence from panel data. Journal of Finance 47, 1425-1460.

Whited, T., Wu, G., 2006. Financial constraints risk. Review of Financial Studies 19, $531-559$. 


\section{Table 1: Ratio of Used Capital Expenditures to Total Capital Expenditures across Asset, Employment, and Sales Deciles}

The table describes the amount of capital expenditures on used capital as percentage of total capital expenditures for firms with employees across asset, employment, and sales deciles for capital overall and across asset deciles for structures and equipment separately. We use the 1993-2002 ACES micro data for all industries (due to data availability, we use only the 1993-1996 ACES when using employment and only the 1996-2002 ACES when using sales). We use the firm assets at the beginning of the year as the measure of assets and exclude firms with zero assets. We use the number of employees for employment and the total domestic sales, operating receipts, and revenue for the entire company as sales. We exclude observations for which used capital expenditures on capital overall, structures, and equipment are missing as well as observations for which capital expenditures on structures or equipment are zero. There are an average of 4479,3753 , and 4757 observations per year, respectively. We compute the average ratio of used capital expenditures to total capital expenditures in each size decile for each year and report the average of these average ratios across years for each size decile. We also report the lower cutoffs for each decile.

\begin{tabular}{c|cccc|cc|cc}
\hline \multirow{2}{*}{ Decile } & \multicolumn{4}{|c|}{ By Assets } & \multicolumn{2}{c|}{ By Employment } & \multicolumn{2}{c}{ By Sales } \\
& $\begin{array}{c}\text { Decile } \\
\text { cutoff } \\
\text { (millions) }\end{array}$ & $\begin{array}{c}\text { Used } \\
\text { capital } \\
\text { (percent) }\end{array}$ & $\begin{array}{c}\text { Used } \\
\text { structures } \\
\text { (percent) }\end{array}$ & $\begin{array}{c}\text { Used } \\
\text { equipment } \\
\text { (percent) }\end{array}$ & $\begin{array}{c}\text { Decile } \\
\text { cutoff } \\
\text { (thousands) }\end{array}$ & $\begin{array}{c}\text { Used } \\
\text { capital } \\
\text { (percent) }\end{array}$ & $\begin{array}{c}\text { Decile } \\
\text { cutoff } \\
\text { (millions) }\end{array}$ & $\begin{array}{c}\text { Used } \\
\text { capital } \\
\text { (percent) }\end{array}$ \\
\hline 1st & 0 & $27.79 \%$ & $28.77 \%$ & $26.21 \%$ & 0 & $30.27 \%$ & 0 & $20.38 \%$ \\
2nd & 0.10 & $20.17 \%$ & $21.69 \%$ & $17.32 \%$ & 0.01 & $17.86 \%$ & 0.53 & $23.28 \%$ \\
3rd & 0.36 & $18.51 \%$ & $21.43 \%$ & $15.36 \%$ & 0.03 & $16.31 \%$ & 2.05 & $18.93 \%$ \\
4th & 1.04 & $17.13 \%$ & $20.20 \%$ & $14.46 \%$ & 0.07 & $13.54 \%$ & 5.97 & $16.79 \%$ \\
5th & 2.94 & $16.14 \%$ & $20.08 \%$ & $12.97 \%$ & 0.18 & $11.69 \%$ & 13.65 & $16.40 \%$ \\
6th & 7.55 & $15.07 \%$ & $19.04 \%$ & $12.44 \%$ & 0.52 & $11.92 \%$ & 27.4 & $14.86 \%$ \\
7th & 16.89 & $12.69 \%$ & $16.15 \%$ & $10.64 \%$ & 0.67 & $10.52 \%$ & 51.15 & $13.21 \%$ \\
8th & 34.46 & $12.16 \%$ & $15.80 \%$ & $9.72 \%$ & 0.92 & $10.85 \%$ & 94.93 & $12.67 \%$ \\
9th & 69.24 & $11.22 \%$ & $15.33 \%$ & $9.18 \%$ & 1.45 & $10.33 \%$ & 186.51 & $11.81 \%$ \\
10th & 186.55 & $10.10 \%$ & $13.04 \%$ & $8.34 \%$ & 3.09 & $9.23 \%$ & 490.25 & $9.94 \%$ \\
\hline
\end{tabular}




\section{Table 2: Fraction Used Capital Expenditures Conditional on Financial Vari- ables}

The table shows the fraction of capital expenditures on used capital depending on various financial variables. We report both the conditional mean of the deviations of firms' used capital expenditures from the industry mean used capital expenditure and the conditional mean of the firms' used capital expenditures. We compute the conditional means for the top and bottom quartile by assets, the Kaplan/Zingales (1997) index, and the Whited/Wu (2006) index, as well as conditional means depending on whether firms pay dividends or not and depending on whether firms' credit ratings are investment grade or not. Data is micro data from a cross section of firms from the 1998 ACES for the dependent variable, used capital expenditures over total capital expenditures, and the industry dummies, and from Compustat for financial variables. For a detailed definition of the variables see the description in Table 3.

\section{Panel A: Used Capital Expenditures as Deviation from Industry Mean}

\begin{tabular}{l|cc} 
& More constrained & Less constrained \\
\hline Assets (smallest vs. largest quartile) & $8.55 \%$ & $-12.29 \%$ \\
Sales (smallest vs. largest quartile) & $26.46 \%$ & $-26.44 \%$ \\
Employment (smallest vs. largest quartile) & $3.03 \%$ & $-24.17 \%$ \\
Kaplan/Zingales (1997) index (highest vs. lowest quartile) & $20.86 \%$ & $-3.25 \%$ \\
Whited/Wu (2006) index (highest vs. lowest quartile) & $11.47 \%$ & $-18.76 \%$ \\
Dividends (zero vs. positive) & $6.19 \%$ & $-4.61 \%$ \\
Credit rating (non-investment vs. investment grade) & $-4.76 \%$ & $-15.43 \%$
\end{tabular}

\section{Panel B: Fraction Used Capital Expenditures}

\begin{tabular}{l|cc} 
& More constrained & Less constrained \\
\hline Assets (smallest vs. largest quartile) & $12.82 \%$ & $11.11 \%$ \\
Sales (smallest vs. largest quartile) & $15.57 \%$ & $8.56 \%$ \\
Employment (smallest vs. largest quartile) & $14.62 \%$ & $8.41 \%$ \\
Kaplan/Zingales (1997) index (highest vs. lowest quartile) & $14.91 \%$ & $10.07 \%$ \\
Whited/Wu (2006) index (highest vs. lowest quartile) & $13.08 \%$ & $8.51 \%$ \\
Dividends (zero vs. positive) & $12.36 \%$ & $11.81 \%$ \\
Credit rating (non-investment vs. investment grade) & $12.39 \%$ & $11.21 \%$
\end{tabular}




\section{Table 3: Descriptive Statistics}

The table shows the descriptive statistics for the variables used in the regressions of the fraction of capital expenditures on used capital on various financial and control variables. Data is micro data from a cross section of firms from the 1998 ACES for the dependent variable, used capital expenditures over total capital expenditures, firm age, and for the industry dummies, and from Compustat for financial variables. Used capital expenditures and total capital expenditures are from Item 2 of the 1998 ACES (row 22 and 20, respectively). Assets are Item 6 (Assets - Total/Liabilities and Stockholders' Equity - Total); dividends are Item 21 (Dividends - Common) plus (where available) Item 19 (Dividends Preferred); long-term debt is Item 9 (Long-Term Debt - Total); cash flow is Item 18 (Income Before Extraordinary Items) plus Item 14 (Depreciation and Amortization); Tobin's $q$ is Item 6 plus Item 24 (Price - Close) times Item 25 (Common Shares Outstanding) minus Item 60 (Common Equity - Total) minus Item 74 (Deferred Taxes - Balance Sheet) all divided by Item 6; cash is Item 1 (Cash and ShortTerm Investments). The firm age variable is the age of the firm according to Census data. The mean and standard deviation of sales growth is computed using the logarithmic growth rates of Item 12 (Net Sales) using data for years 1993 to 1998. The marginal tax rate is the before interest expense marginal tax rate (see Graham, Lemmon, and Schallheim, 1998). PP\&E is Item 8 (Property, Plant \& Equipment - Net) and employees are Item 29 (Employees). R\&D expense is Item 46 (Research \& Development Expense). All variables (except firm age and the marginal tax rate) are Winsorized at the 1st and 99th percentile.

\begin{tabular}{l|crrr}
\hline Dependent Variables & Observations & Mean & Std. dev. & Median \\
\hline used to total capital expenditures overall & 1101 & $12 \%$ & $21 \%$ & $2 \%$ \\
used to total capital expenditures on structures & 838 & $21 \%$ & $32 \%$ & $0 \%$ \\
used to total capital expenditures on equipment & 883 & $10 \%$ & $19 \%$ & $1 \%$ \\
Independent Variables & & & & \\
\hline log(assets) & 1101 & 6.59 & 1.83 & 6.50 \\
dividends/assets & 1101 & $1 \%$ & $2 \%$ & $0 \%$ \\
long-term debt/assets & 1098 & $24 \%$ & $21 \%$ & $20 \%$ \\
cash flow/assets & 1076 & $7 \%$ & $9 \%$ & $8 \%$ \\
$q$ & 892 & 1.62 & 1.04 & 1.26 \\
cash/assets & 1101 & $8 \%$ & $11 \%$ & $3 \%$ \\
firm age & 1096 & 16.85 & 7.07 & 22 \\
std. dev. sales growth & 805 & $13 \%$ & $11 \%$ & $10 \%$ \\
marginal tax rate & 805 & $31 \%$ & $9 \%$ & $35 \%$ \\
PP\&E/employees (in millions) & 978 & 0.106 & 0.240 & 0.035 \\
R\&D expense/sales & 1064 & $1.52 \%$ & $4.31 \%$ & $0 \%$ \\
sales/employees (in millions) & 1001 & 0.232 & 0.224 & 0.169 \\
mean sales growth & 905 & $12 \%$ & $15 \%$ & $10 \%$ \\
\hline
\end{tabular}




\section{Table 4: Regression Results: Fraction Used Capital Expenditures for Capital Overall}

The table shows the coefficients of a regression of the fraction of capital expenditures on used capital (for capital overall) on various financial and control variables (controlling for industry dummies at the three digit NAICS code level). Heteroscedasticity corrected standard errors are in parenthesis. Data is micro data from a cross section of firms from the 1998 ACES for the dependent variable, used capital expenditures over total capital expenditures, firm age, and the industry dummies, and from Compustat for financial variables, tax variables, and the standard deviation of sales growth. For a detailed definition of the variables see the description in Table 3 . Statistical significance at the $1 \%, 5 \%$, and $10 \%$ level is indicated by ${ }^{* * *},{ }^{* *}$, and ${ }^{*}$, respectively.

\begin{tabular}{|c|c|c|c|c|c|c|c|c|c|}
\hline Regression & 1 & 2 & 3 & 4 & 5 & 6 & 7 & 8 & 9 \\
\hline $\log ($ assets $)$ & $\begin{array}{l}-0.0085^{* *} \\
(0.0037)\end{array}$ & $\begin{array}{l}-0.0098^{* * *} \\
(0.0036)\end{array}$ & $\begin{array}{l}-0.0105^{* * *} \\
(0.0037)\end{array}$ & $\begin{array}{l}-0.0142^{* * *} \\
(0.0040)\end{array}$ & $\begin{array}{l}-0.0102^{* * *} \\
(0.0037)\end{array}$ & $\begin{array}{l}-0.0181^{* * *} \\
(0.0041)\end{array}$ & $\begin{array}{l}-0.0170^{* * *} \\
(0.0054)\end{array}$ & $\begin{array}{l}-0.0221^{* * *} \\
(0.0050)\end{array}$ & $\begin{array}{l}-0.0179^{* * *} \\
(0.0052)\end{array}$ \\
\hline dividends/assets & $\begin{array}{l}-0.6037^{* *} \\
(0.3022)\end{array}$ & & & & & $\begin{array}{l}-0.2504 \\
(0.3375)\end{array}$ & $\begin{array}{l}-0.0265 \\
(0.4547)\end{array}$ & $\begin{array}{l}-0.0090 \\
(0.4381)\end{array}$ & $\begin{array}{l}-0.0706 \\
(0.4264)\end{array}$ \\
\hline long-term debt/assets & & $\begin{array}{l}0.0933^{* *} \\
(0.0376)\end{array}$ & & & & $\begin{array}{l}0.1465^{* * *} \\
(0.0444)\end{array}$ & $\begin{array}{l}0.1300^{* * *} \\
(0.0469)\end{array}$ & $\begin{array}{l}0.1706^{* * *} \\
(0.0515)\end{array}$ & $\begin{array}{l}0.1343^{* * *} \\
(0.0423)\end{array}$ \\
\hline cash flow/assets & & & $\begin{array}{l}0.0506 \\
(0.0783)\end{array}$ & & & $\begin{array}{l}0.0996 \\
(0.0812)\end{array}$ & $\begin{array}{l}0.1397 \\
(0.1112)\end{array}$ & $\begin{array}{l}0.0851 \\
(0.1124)\end{array}$ & $\begin{array}{l}0.1400 \\
(0.1035)\end{array}$ \\
\hline$q$ & & & & $\begin{array}{l}0.0080 \\
(0.0069)\end{array}$ & & $\begin{array}{l}0.0156^{*} \\
(0.0080)\end{array}$ & $\begin{array}{l}0.0117 \\
(0.0091)\end{array}$ & $\begin{array}{l}0.0215^{* *} \\
(0.0098)\end{array}$ & $\begin{array}{l}0.0075 \\
(0.0083)\end{array}$ \\
\hline cash/assets & & & & & $\begin{array}{l}-0.0908^{* *} \\
(0.0450)\end{array}$ & $\begin{array}{l}-0.0655 \\
(0.0561)\end{array}$ & $\begin{array}{l}-0.0586 \\
(0.0738)\end{array}$ & $\begin{array}{l}-0.0582 \\
(0.0708)\end{array}$ & $\begin{array}{l}-0.0504 \\
(0.0739)\end{array}$ \\
\hline firm age & & & & & & & $\begin{array}{l}-0.0018 \\
(0.0016)\end{array}$ & & \\
\hline$\sigma($ sales growth $)$ & & & & & & & $\begin{array}{l}0.1193 \\
(0.0918)\end{array}$ & & \\
\hline mrg. tax rate & & & & & & & & $\begin{array}{l}0.0552 \\
(0.0982)\end{array}$ & \\
\hline PP\&E/employees & & & & & & & & & $\begin{array}{l}0.0412 \\
(0.0677)\end{array}$ \\
\hline R\&D expense/sales & & & & & & & & & $\begin{array}{l}0.1556 \\
(0.1944)\end{array}$ \\
\hline sales/employees & & & & & & & & & $\begin{array}{l}-0.0984^{*} \\
(0.0542)\end{array}$ \\
\hline$\mu($ sales growth $)$ & & & & & & & & & $\begin{array}{l}0.0834 \\
(0.0643)\end{array}$ \\
\hline $\operatorname{adj} \cdot R^{2}$ & $11.70 \%$ & $12.27 \%$ & $7.71 \%$ & $14.68 \%$ & $11.69 \%$ & $12.59 \%$ & $8.72 \%$ & $14.20 \%$ & $12.03 \%$ \\
\hline Observations & 1101 & 1098 & 1076 & 892 & 1101 & 871 & 638 & 710 & 671 \\
\hline
\end{tabular}




\section{Table 5: Regression Results: Fraction Used Capital Expenditures for Struc- tures and Equipment}

The table shows the coefficients of a regression of the fraction of capital expenditures on used capital (for structures and equipment, respectively) on various financial variables (controlling for industry dummies at the three digit NAICS code level). Heteroscedasticity corrected standard errors are in parenthesis. Data is micro data from a cross section of firms from the 1998 ACES for the dependent variable, used capital expenditures over total capital expenditures, and the industry dummies, and from Compustat for financial variables. For a detailed definition of the variables see the description in Table 3. Statistical significance at the $1 \%, 5 \%$, and $10 \%$ level is indicated by ${ }^{* * *},{ }^{* *}$, and ${ }^{*}$, respectively.

Panel A: Structures

\begin{tabular}{|c|c|c|c|c|c|c|}
\hline Regression & 1 & 2 & 3 & 4 & 5 & 6 \\
\hline $\log$ (assets) & $\begin{array}{l}-0.0134^{*} \\
(0.0072)\end{array}$ & $\begin{array}{l}-0.0150^{* *} \\
(0.0072)\end{array}$ & $\begin{array}{l}-0.0163^{* *} \\
(0.0072)\end{array}$ & $\begin{array}{l}-0.0255^{* * *} \\
(0.0082)\end{array}$ & $\begin{array}{l}-0.0151^{* *} \\
(0.0074)\end{array}$ & $\begin{array}{l}-0.0299^{\text {*** }} \\
(0.0081)\end{array}$ \\
\hline dividends/assets & $\begin{array}{l}-1.2835^{* *} \\
(0.5399)\end{array}$ & & & & & $\begin{array}{c}-0.7835 \\
(0.5862)\end{array}$ \\
\hline long-term debt/assets & & $\begin{array}{l}0.1616^{* *} \\
(0.0757)\end{array}$ & & & & $\begin{array}{c}0.1874^{* *} \\
(0.0879)\end{array}$ \\
\hline cash flow/assets & & & $\begin{array}{l}0.0083 \\
(0.1847)\end{array}$ & & & $\begin{array}{l}0.1856 \\
(0.1959)\end{array}$ \\
\hline$q$ & & & & $\begin{array}{l}0.0017 \\
(0.0137)\end{array}$ & & $\begin{array}{l}0.0118 \\
(0.0156)\end{array}$ \\
\hline cash/assets & & & & & $\begin{array}{l}-0.0486 \\
(0.1178)\end{array}$ & $\begin{array}{l}0.0140 \\
(0.1500)\end{array}$ \\
\hline $\operatorname{adj} . R^{2}$ & $2.69 \%$ & $3.08 \%$ & $0.92 \%$ & $4.30 \%$ & $2.24 \%$ & $3.89 \%$ \\
\hline Observations & 838 & 835 & 815 & 664 & 838 & 643 \\
\hline
\end{tabular}

Panel B: Equipment

\begin{tabular}{|c|c|c|c|c|c|c|}
\hline Regression & 1 & 2 & 3 & 4 & 5 & 6 \\
\hline $\log ($ assets $)$ & $\begin{array}{l}-0.0087^{* *} \\
(0.0038)\end{array}$ & $\begin{array}{l}-0.0093^{* *} \\
(0.0037)\end{array}$ & $\begin{array}{l}-0.0097^{* * *} \\
(0.0038)\end{array}$ & $\begin{array}{l}-0.0109^{* * *} \\
(0.0041)\end{array}$ & $\begin{array}{l}-0.0097^{* * *} \\
(0.0038)\end{array}$ & $\begin{array}{l}-0.0158^{* * *} \\
(0.0043)\end{array}$ \\
\hline dividends/assets & $\begin{array}{l}-0.0315 \\
(0.3157)\end{array}$ & & & & & $\begin{array}{l}0.2424 \\
(0.3572)\end{array}$ \\
\hline long-term debt/assets & & $\begin{array}{l}0.1158^{* * *} \\
(0.0398)\end{array}$ & & & & $\begin{array}{l}0.1425^{* * *} \\
(0.0442)\end{array}$ \\
\hline cash flow/assets & & & $\begin{array}{l}0.0588 \\
(0.0794)\end{array}$ & & & $\begin{array}{l}0.1431^{*} \\
(0.0763)\end{array}$ \\
\hline$q$ & & & & $\begin{array}{l}0.0040 \\
(0.0072)\end{array}$ & & $\begin{array}{l}0.0061 \\
(0.0080)\end{array}$ \\
\hline cash/assets & & & & & $\begin{array}{c}-0.0973^{* *} \\
(0.0482)\end{array}$ & $\begin{array}{l}-0.0415 \\
(0.0564)\end{array}$ \\
\hline $\operatorname{adj} . R^{2}$ & $10.71 \%$ & $12.01 \%$ & $10.95 \%$ & $12.02 \%$ & $11.00 \%$ & $14.34 \%$ \\
\hline Observations & 883 & 883 & 871 & 715 & 883 & 706 \\
\hline
\end{tabular}




\section{Figure 1: Investment in New and Used Capital}

Top Left Panel: Investment in new capital (dash dotted), used capital (solid), and total investment (dotted) as a function of the amount of internal funds. Middle Left Panel: Investment in used capital as percentage of total investment. Bottom Left Panel: Agent specific shadow price of new capital (dotted) and used capital (solid). Top Right Panel: Borrowing. Middle Right Panel: Multiplier on the borrowing constraint $\lambda_{b}(e)$ (normalized by the marginal utility of consumption at time 0 ) as a function of the amount of internal funds.

Parameter values: Preferences: $u(c)=\frac{c^{1-\gamma}}{1-\gamma}, \beta=0.96, \gamma=2$; Technology: $\alpha=0.33, \delta=0.12$, $m_{u}=0.5$; Collateralization Rate: $\theta=0.2$; Discretized State Space: $i_{u}, i_{n} \in[0: 0.002: 0.5], b \in$ $[-0.2: 0.002: 0,0.001: 0.001: 0.05] ;$ Distribution of Internal Funds: $\mathcal{E}=[0.05: 0.05: 1.75], \pi(e) \propto$ $[\exp (-0.05), \ldots, \exp (-1.75)]$.

Equilibrium implications: price of used capital: $p_{u}=0.5485>1-\beta m_{u}=0.52$; levels of capital: $\bar{k}=0.3914, \overline{\bar{k}}=0.4554$.
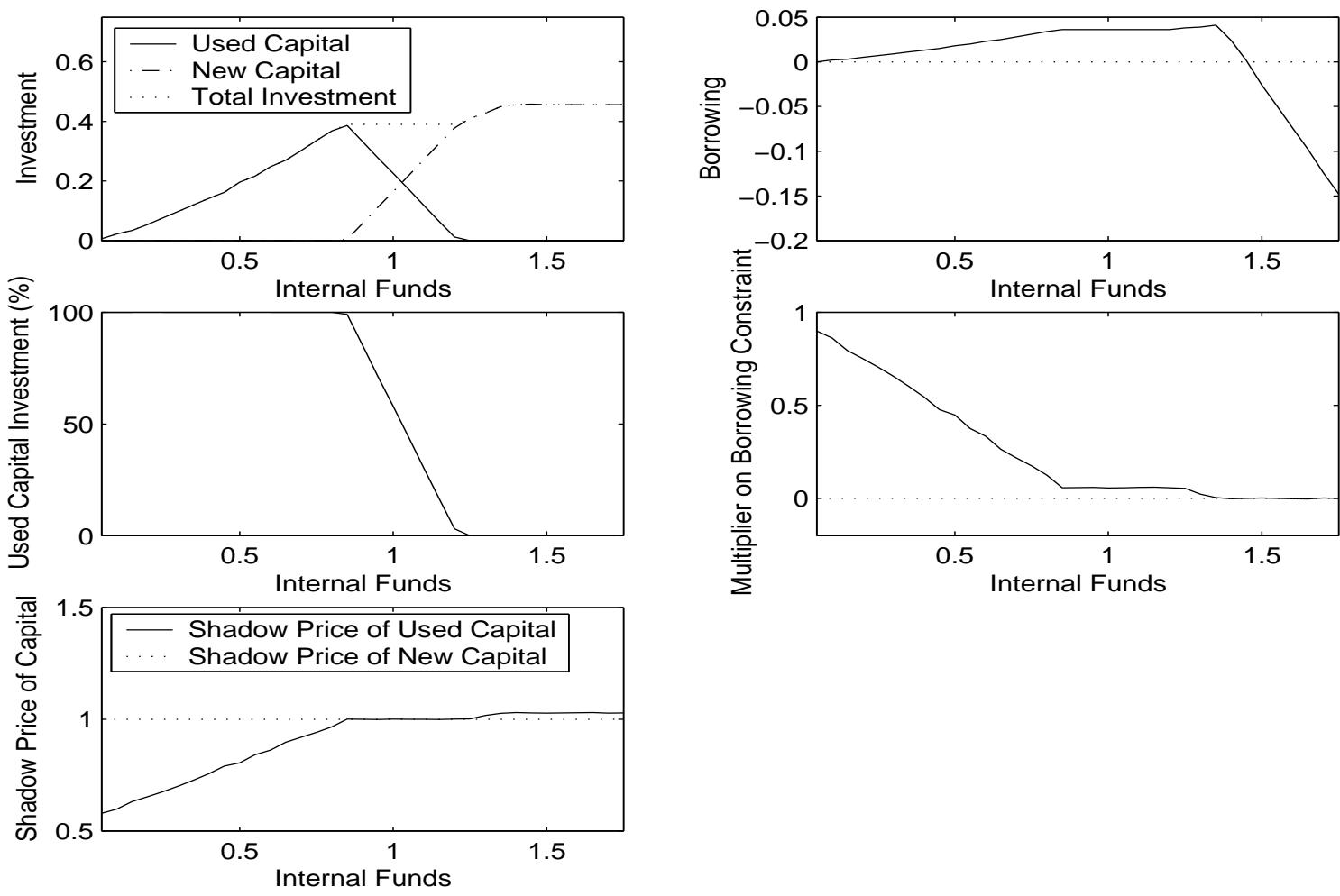


\section{Figure 2: Fraction of Trucks Purchased Used versus Fleet Size}

Plotted series are the fraction of trucks purchased used as percentage of all trucks purchased new or used graphed against the natural logarithm of the fleet size, which is the number of trucks and trailers operated by a truck owner for his/her entire operation. We use the midpoint of the reporting category as the fleet size. Solid bold line is the fraction of all trucks purchased used and dotted lines are fraction of trucks purchased used for 32 different body types of trucks (e.g., pickup, panel or van, ...). Data is from the public use micro data file of the 1997 VIUS. We report results for trucks reported as operated for business use only.

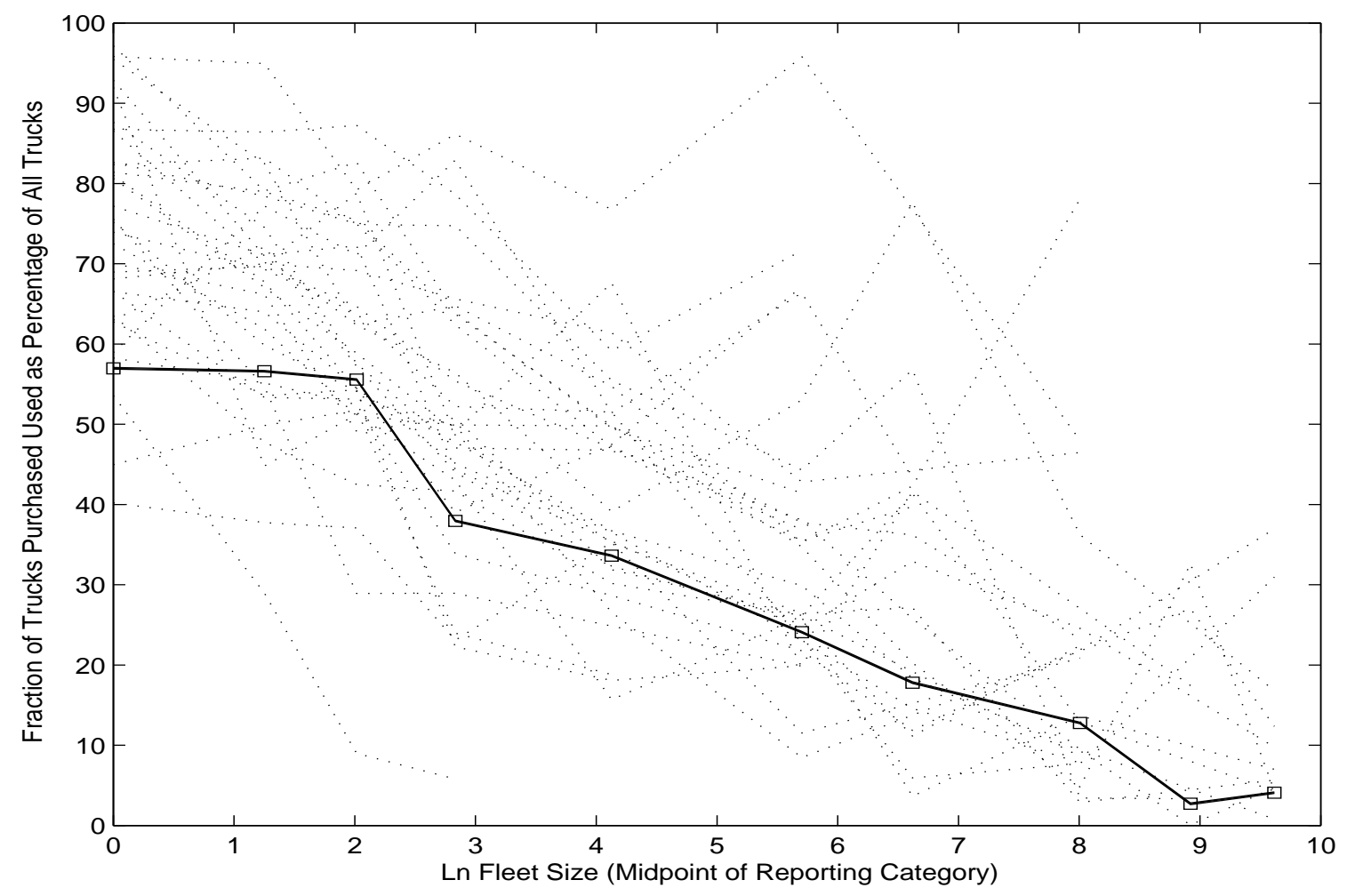




\section{Figure 3: Fraction of Used Capital Expenditures across Asset Deciles}

Fraction of used capital expenditures relative to total capital expenditures in percent graphed across asset deciles: Percentage used capital overall (solid), percentage used structures (dashed), and percentage used equipment (dash dotted). We use the 1993-2002 ACES micro data. See Table 1 for a detailed description of the data construction.

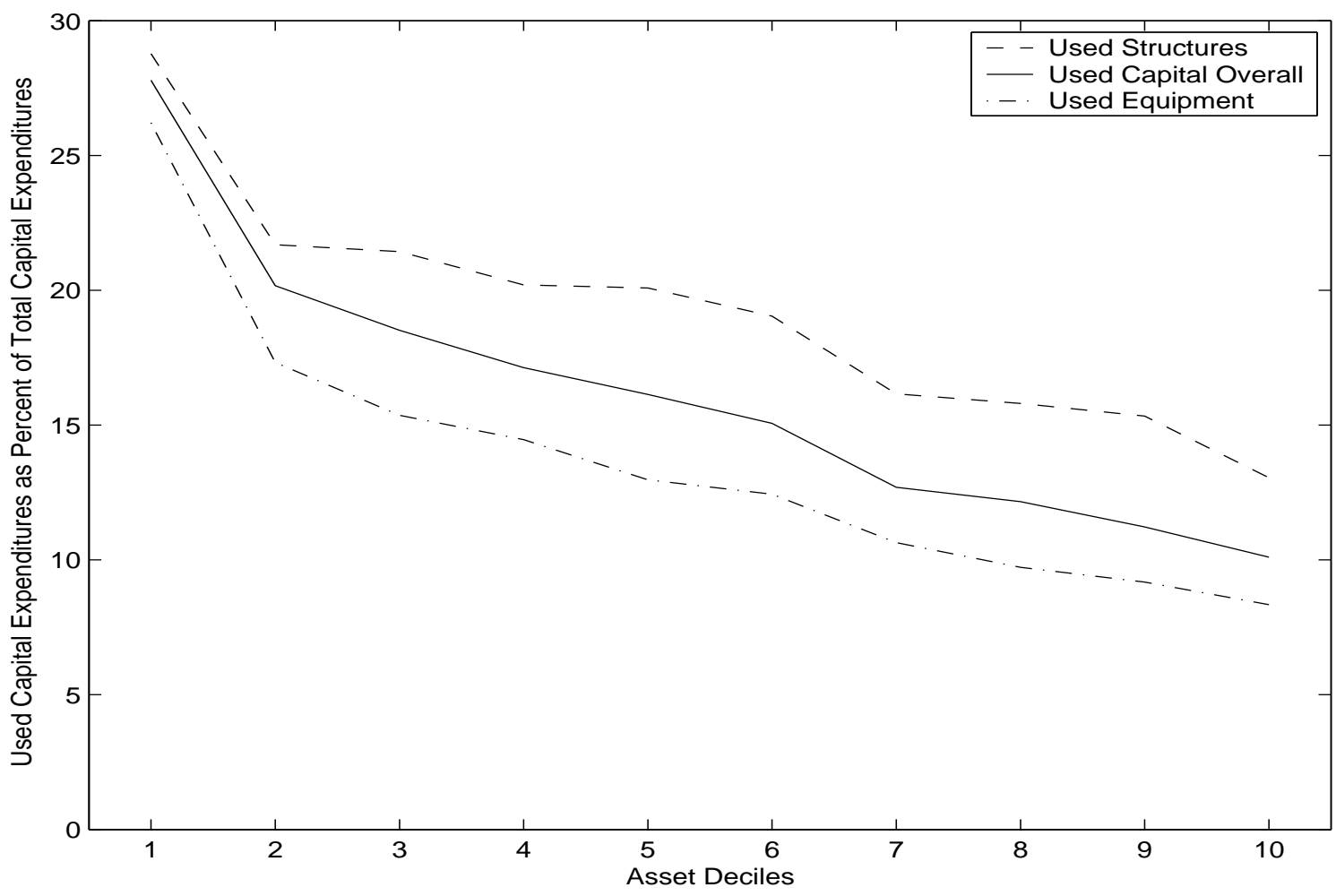

